www.mdpi.com/journal/applsci

Article

\title{
Reduction and Immobilization of Potassium Permanganate on Iron Oxide Catalyst by Fluidized-Bed Crystallization Technology
}

\section{Guang-Xia Li ${ }^{1}$, Yao-Hui Huaug ${ }^{2,3, *}$, Teng-Chien Chen ${ }^{2}$, Yu-Jen Shih ${ }^{2}$ and Hui Zhang ${ }^{1}$}

1 Department of Environmental Engineering, Wuhan University, P.O. Box C319 Luoyu Road 129\#, Wuhan 430079, China; E-Mails: liguangxiamanman@gmail.com (G.-X.L.); eeng@whu.edu.cn (H.Z.)

2 Department of Chemical Engineering, National Cheng Kung University, Tainan 701, Taiwan; E-Mails: joily@ceg.com.tw (T.-C.C.); mcdyessjin@gmail.com (Y.-J.S.)

3 Sustainable Environment Research Center, National Cheng Kung University, Tainan 701, Taiwan

* Author to whom correspondence should be addressed; E-Mail: yhhuang@mail.ncku.edu.tw; Tel.: +886-6-275-7575x626-36; Fax: +886-6-234-4496.

Received: 9 February 2012; in revised form: 21 February 2012 / Accepted: 23 February 2012 / Published: 1 March 2012

\begin{abstract}
A manganese immobilization technology in a fluidized-bed reactor (FBR) was developed by using a waste iron oxide (i.e., BT-3) as catalyst which is a by-product from the fluidized-bed Fenton reaction (FBR-Fenton). It was found that BT-3 could easily reduce potassium permanganate $\left(\mathrm{KMnO}_{4}\right)$ to $\mathrm{MnO}_{2}$. Furthermore, $\mathrm{MnO}_{2}$ could accumulate on the surface of BT-3 catalyst to form a new Fe-Mn oxide. Laboratory experiments were carried out to investigate the $\mathrm{KMnO}_{4}$-reduction mechanism, including the effect of $\mathrm{KMnO}_{4}$ concentration, BT-3 dosage, and operational solution $\mathrm{pH}$. The results showed that the $\mathrm{pH}$ solution was a significant factor in the reduction of $\mathrm{KMnO}_{4}$. At the optimum level, $\mathrm{pH}_{\mathrm{f}} 6$, $\mathrm{KMnO}_{4}$ was virtually reduced in $10 \mathrm{~min}$. A pseudo-first order reaction was employed to describe the reduction rate of $\mathrm{KMnO}_{4}$.
\end{abstract}

Keywords: Fluidized-Bed Reactor (FBR); iron oxide; potassium permanganate 


\section{Introduction}

Recently, numerous researches have focused on adsorptive arsenic removal, in which iron oxide was considered to be an appropriate adsorbent due to its high affinity [1-7]. However, the As(III) adsorption is less effective than the $\mathrm{As}(\mathrm{V})$ adsorption by adsorbents in natural water. Arsenite $[\mathrm{As}(\mathrm{III})]$ is much more toxic, soluble and mobile than arsenate $[\mathrm{As}(\mathrm{V})]$. Manganese oxides have been extensively investigated as oxidizing agents for arsenite; the reaction is written as follows [8-10]:

$$
\mathrm{MnO}_{2}+\mathrm{H}_{3} \mathrm{AsO}_{3}+2 \mathrm{H}^{+}=\mathrm{Mn}^{2+}+\mathrm{H}_{3} \mathrm{AsO}_{4}+\mathrm{H}_{2} \mathrm{O}
$$

Accordingly, a novel binary oxide concept in which the Mn-O catalyzed the As(III) pre-oxidation to $\mathrm{As}(\mathrm{V})$ and the Fe-O functioned as adsorbent, was therefore proposed [11,12]. To our knowledge, the Mn-Fe binary oxide materials was easily prepared by the co-precipitation methods, where the Mn reduction by ferrous is dependent on the solution $\mathrm{pH}[12,13]$ :

$$
3 \mathrm{Fe}^{2+}+\mathrm{MnO}_{4}{ }^{-}+4 \mathrm{OH}^{-}+3 \mathrm{H}_{2} \mathrm{O} \rightarrow 3 \mathrm{Fe}(\mathrm{OH})_{3}(\mathrm{~s})+\mathrm{MnO}_{2}(\mathrm{~s})+\mathrm{H}^{+}
$$

However, the powder product of micrometers in size was difficul for solid-liquid separation. Based on the perspective of Mn-Fe binary oxide for arsenic removal, this study applied a millimeter scale iron oxide (BT-3) as support and aims at the synthesis of manganese oxides on its surface through the redox of potassium permanganate ${ }^{+}$in a fluidized bed reactor (FBR). The FBR technology could immobilize potassium permanganate onto BT-3, which was a waste iron oxide from real fluidized bed-Fenton (FBR-Fenton) instruments and was mainly composed of poorly crystallized goethite [14].

Therefore, the employment of BT-3 as the support had the advantages of being cost-efficient and facilitated easier separation and disposal during the synthetic process of binary oxide, and during the application for arsenic removal. Our previous studies have explored the ability of BT waste iron oxide as an excellent adsorbent for $\mathrm{F}^{-}, \mathrm{PO}_{4}{ }^{3-}, \mathrm{Cu}^{2+}$, and $\mathrm{Pb}^{2+}$ removal because of its high surface area and porosity nature [14-16]. In this study, we attempted to investigate the feasibility of Mn immobilization onto BT-3 without ferrous addition, and then to develop a novel Mn-Fe binary oxide using fluidized-bed crystallization technology. The characterization of BT-3 was examined first. Then, the Mn removal efficiency in solution was detected as a function of reaction time. Furthermore, the effect of $\mathrm{KMnO}_{4}$ concentration, BT-3 dosage, and initial solution $\mathrm{pH}_{\mathrm{i}}$ was studied through bench scale studies. The optimized parameters were also proposed. Finally, a possible mechanism to synthesize the novel $\mathrm{Mn}-\mathrm{Fe}$ was rationally proposed via the kinetic study of Mn removal.

\section{Material and Methods}

The experimental set-up was composed of a $500 \mathrm{~mL}$ FBR and a pump which are shown in Figure 1. $40 \mathrm{~g}$ ( or $100 \mathrm{~g}$ ) of the fluidized media (BT-3) was placed into the reactor. The dimensions of the reactor were $480 \mathrm{~cm}^{3}$ at high $80 \mathrm{~cm}$. The input flow rate was $60 \mathrm{~mL} / \mathrm{min}$ and the reflux flow rate was $150 \mathrm{~mL} / \mathrm{min}$. The concentration of the potassium permanganate was around $20 \mathrm{mg} / \mathrm{L}$ to $70 \mathrm{mg} / \mathrm{L}$. The potassium permanganate $\left(\mathrm{KMnO}_{4}\right)$ in the aqueous solution was fresh prepared from $\mathrm{KMnO}_{4}$ (Merck), and the solution $\mathrm{pH}_{\mathrm{f}}$ was adjusted using $\mathrm{NaOH}$ and $\mathrm{HClO}_{4}$. At the selected time intervals, the samples were withdrawn from the top of the FBR by syringe. Each sample was filtrated immediately with a $0.45 \mathrm{~mm}$ membrane and measured the concentration of $\mathrm{KMnO}_{4}$ with a UV-vis detector. 
The UV-vis detector was scanning from 200 to $800 \mathrm{~nm}$. The total iron ([Fe]) and manganese ([Mn]) content in samples without filtration were dissolved in concentrated $\mathrm{HCl}$ and then were measured with an atomic absorption spectrophotometer. The immobilizations of potassium permanganate defined as $\left(\left[\mathrm{KMnO}_{4}\right]_{\mathrm{i}}-\left[\mathrm{KMnO}_{4}\right]_{\mathrm{a}}\right) /\left[\mathrm{KMnO}_{4}\right]_{\mathrm{i}}$ indicated that the extent of $\mathrm{Mn}$ immobilized onto support media rather than through the formation of a precipitate in solution. Where $\mathrm{i}$ is the initial concentration, and $\mathrm{a}$ is the $\mathrm{KMnO}_{4}$ concentration after adsorption.

Figure 1. Fluidized bed reactor.

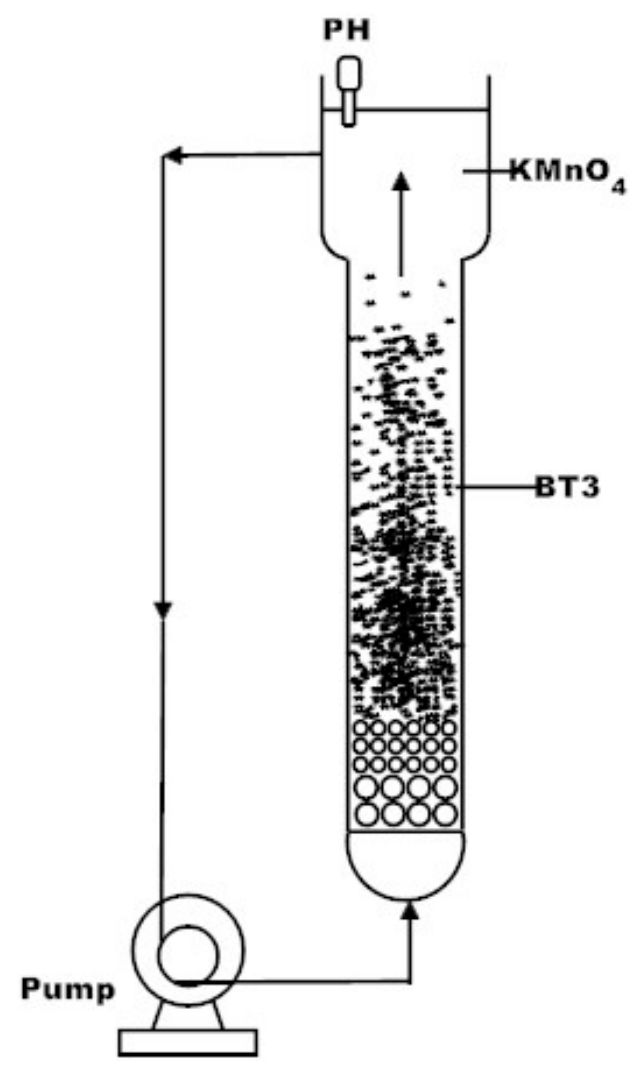

The physic-chemical characteristics of the BT-3 were examined using standard procedures. The morphology of the BT-3 was determined using a JEOL JSM-6700F HR-FESEM. An XRD powder diffraction measurement of BT-3 was performed on a powder diffractometer (Rigaku RX III) using Cu $\mathrm{K} \alpha$ radiation. The accelerating voltage and current were $40 \mathrm{kV}$ and $30 \mathrm{~mA}$. Brunauer-Emmett-Teller (BET) surface area and porosity of the adsorbents were obtained from the isotherms. The surface area of the adsorbents was calculated from the BET equation.

\section{Results and Discussion}

\subsection{Characterization of BT-3}

The properties of BT-3 are listed in Table 1. The average particle size is about $0.5-1 \mathrm{~mm}$. Furthermore, the bulk density and true density are 1.56 and $2.38 \mathrm{~g} \mathrm{~cm}^{-1}$, respectively, which indicates that it is easy to separate from aqueous solutions. The BET specific surface area and pore volume of BT-3 are $174 \mathrm{~m}^{2} / \mathrm{g}$-solid and $0.14 \mathrm{~m}^{2} / \mathrm{g}$-solid, respectively, which reveals the high surface area of BT-3 adsorbent. Figure 2 displays four different magnifications of the morphology of BT-3. An oval shape 
with irregular surface morphology reveals its high surface area. Figure 3 shows the XRD patterns of BT-3. According to the diffraction files of the Joint Committee on Powder Diffraction Standards (JCPDS), the main diffraction peaks of BT-3 adsorbent at $2 \theta=21.5^{\circ}, 36.7^{\circ}$ and $53.3^{\circ}$ adsorbent was identified as the $\alpha-\mathrm{FeOOH}$ phase.

Table 1. Physical properties of BT-3.

\begin{tabular}{lr}
\hline Properties & \multicolumn{1}{c}{ BT-3 } \\
\hline Color & Black \\
Material & Iron oxide \\
Bulk density $\left(\mathrm{g} \cdot \mathrm{cm}^{-1}\right)$ & 1.56 \\
True density $\left(\mathrm{g} \cdot \mathrm{cm}^{-1}\right)$ & 2.38 \\
Total iron content $\left(\mathrm{g} \cdot \mathrm{Kg}^{-1}\right)$ & 649 \\
Specific surface area $(\mathrm{BET})\left(\mathrm{m}^{2} / \mathrm{g}\right.$-solid $)$ & 174 \\
Pore vol. $\left(\mathrm{cm}^{3} / \mathrm{g}\right)$ & 0.14 \\
Average grain size $(\mathrm{mm})$ & $0.5-1$ \\
\hline
\end{tabular}

Figure 2. SEM-EDS images of (a) BT-3, (b) BT-3 covered by $\mathrm{MnO}_{2}$.
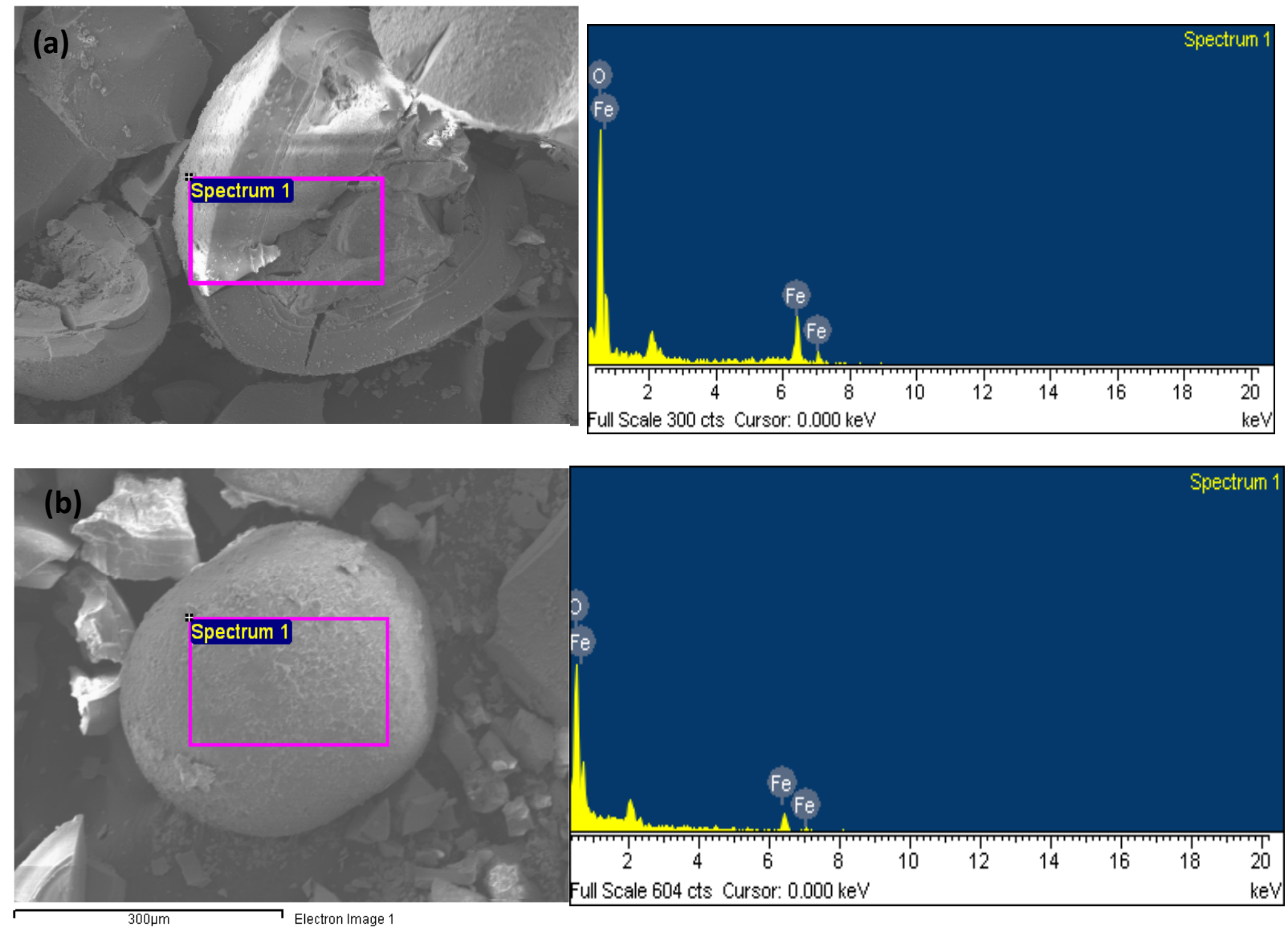
Figure 3. X-ray diffraction pattern of the (a) standard of $\alpha \mathrm{FeOOH}$ (b) BT-3 adsorbent.

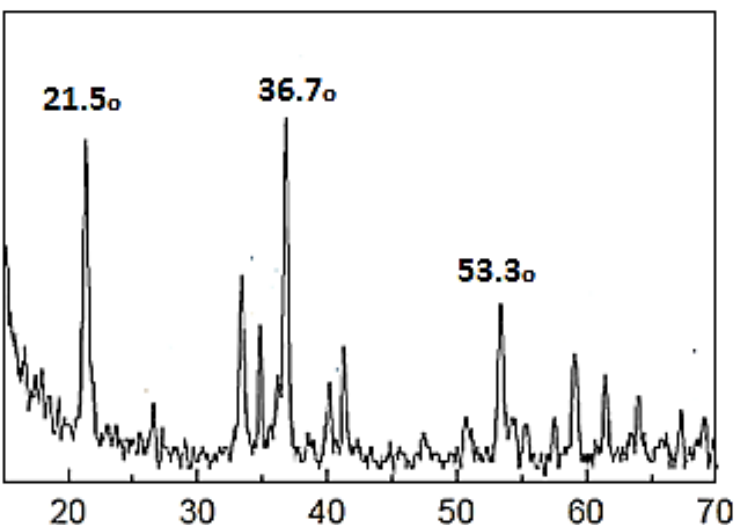

(a)

$2 \theta\left(^{\circ}\right)$

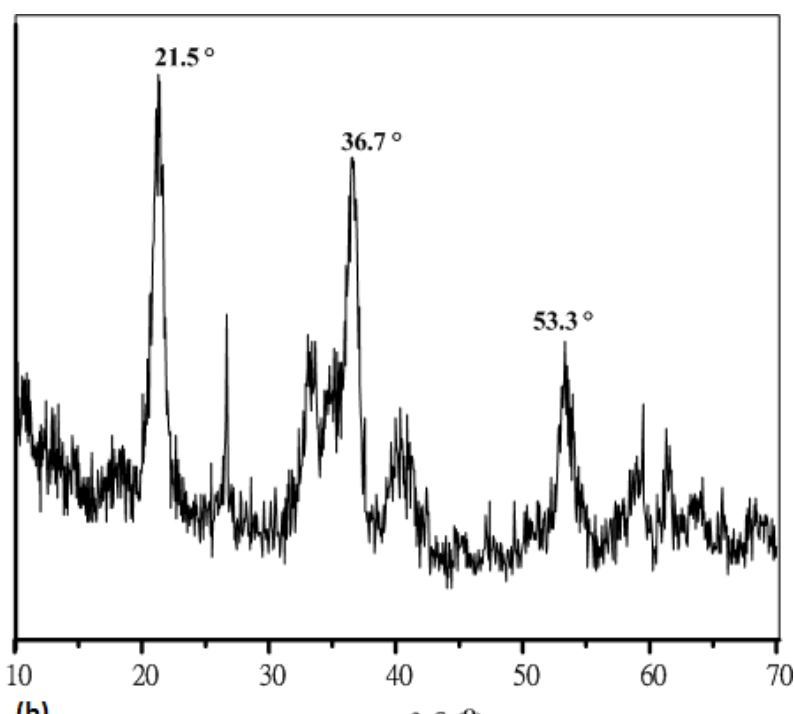

(b)

$2 \theta\left({ }^{\circ}\right)$

\subsection{Effect of $\mathrm{KMnO}_{4}$ Concentration}

Figure 4 shows the effect of initial concentration of $\mathrm{KMnO}_{4}$ on its immobilization efficiency onto BT-3 (BT-3 $\left.=100 \mathrm{~g}, \mathrm{pH}_{\mathrm{i}}=2.5\right)$, in which the reduction rate of $\mathrm{KMnO}_{4}$ decreased with increasing $\mathrm{KMnO}_{4}$ concentration from 20 to $70 \mathrm{mg} / \mathrm{L}$. The time for complete decomposition of $20 \mathrm{mg} / \mathrm{L} \mathrm{KMnO}_{4}$ is $1.5 \mathrm{~h}$, and that with $70 \mathrm{mg} / \mathrm{L} \mathrm{KMnO}_{4}$ is even longer than $6 \mathrm{~h}$.

Figure 4. The effect of initial concentration of $\mathrm{KMnO}_{4}$ on the immobilized efficiency onto BT-3.

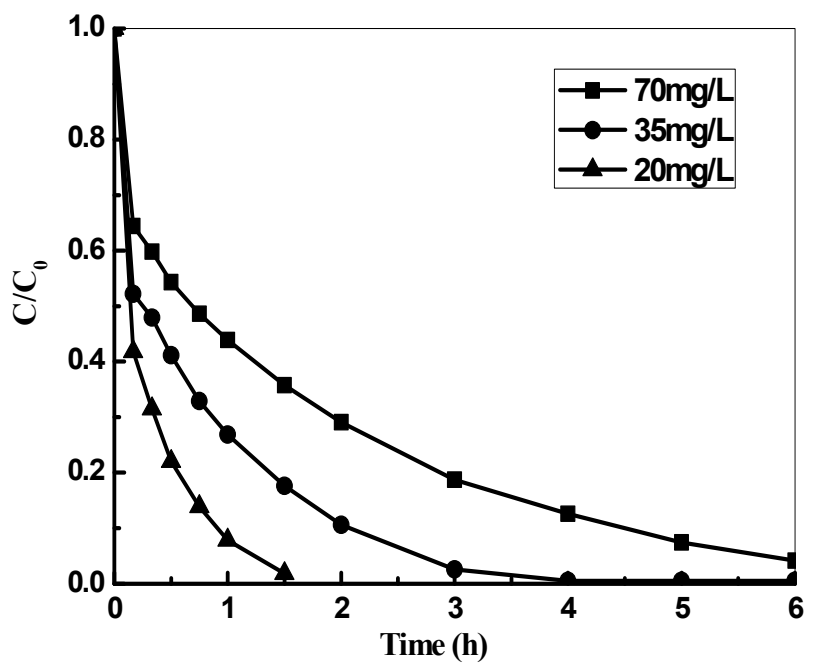

\subsection{Effect of BT-3 Dosage}

As shown in Figure 5, when the $\mathrm{pH}_{\mathrm{i}}$, and the initial concentration of $\mathrm{KMnO}_{4}$ was 2.5 and $35 \mathrm{mg} / \mathrm{L}$, the reduction rate increased with increasing the dose of adsorbent. The maximum removal rate was exhibited at a dosage of $100 \mathrm{~g}$ adsorbent when the initial concentration of $\mathrm{KMnO}_{4}$ was $35 \mathrm{mg} / \mathrm{L}$. Reusing BT3 or higher reusing BT-3 dosage may be attributed to the limitation of catalytic activity sites the BT-3 could provide, which results in a decrease in reduction efficiency of $\mathrm{KMnO}_{4}$. 
Figure 5. Effect of dosage of BT-3 on the immobilization of $\mathrm{KMnO}_{4}$ in binary system.

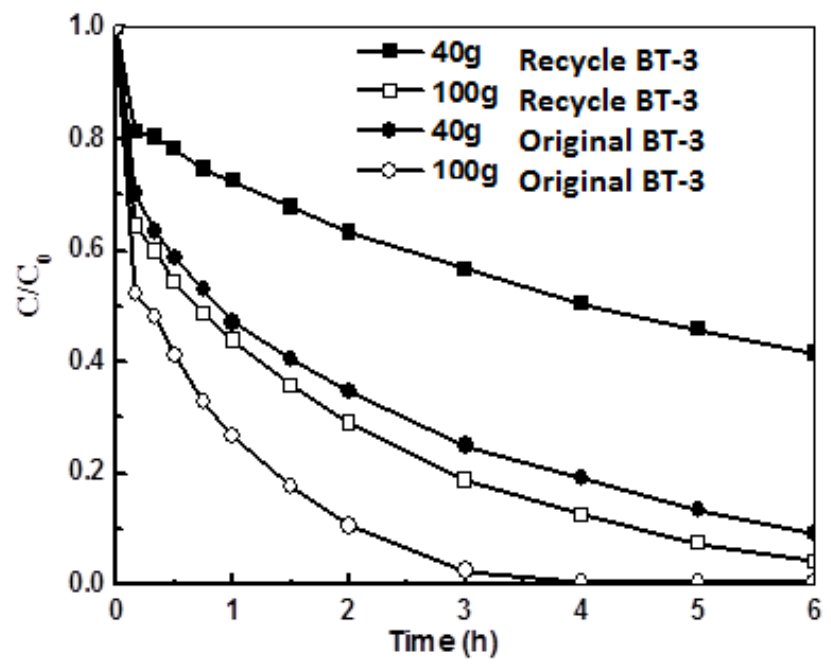

\subsection{Effect of the Operational pH Level}

The solution $\mathrm{pH}$ was a significant factor on the reduction of $\mathrm{KMnO}_{4}$. In this study, we applied four different operation $\mathrm{pH}$ levels which used the $\mathrm{NaOH}$ to adjust the operational $\mathrm{pH}$ level. Figure 6 indicated the effect of different $\mathrm{PH}$ level on the reduction and immobilization of $\mathrm{KMNO}_{4}$ in which the concentration of $\mathrm{KMnO}_{4}$ was $20 \mathrm{mg} / \mathrm{L}$ and the BT-3 dosage was $100 \mathrm{~g}$.

Figure 6. Effect of pHf on the reduction and immobilization of $\mathrm{KMnO}_{4}$.

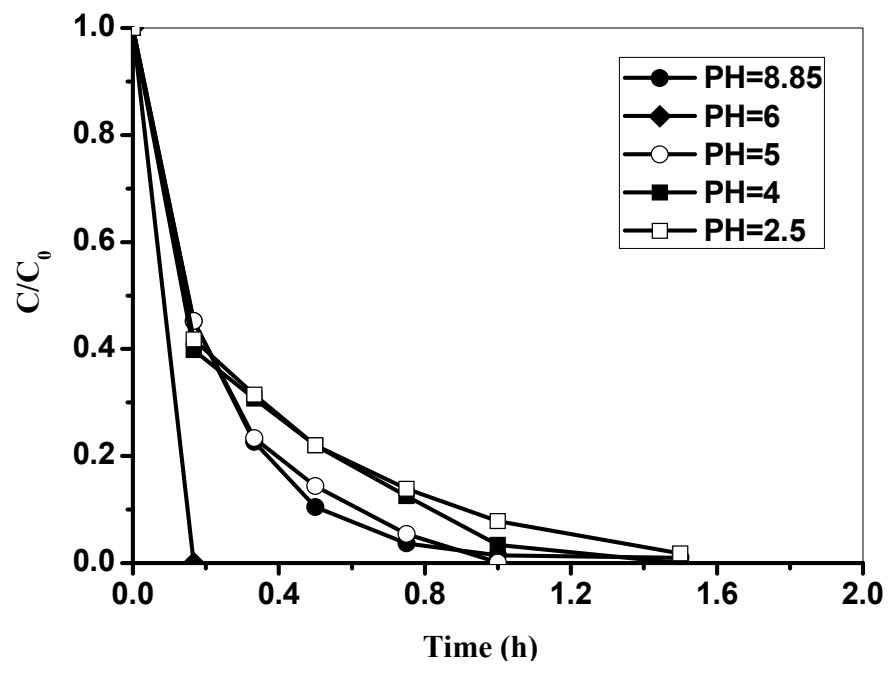

The optimum $\mathrm{pH}_{\mathrm{i}}$ was about 6 , at which $\mathrm{KMnO}_{4}$ could be virtually reduced to $\mathrm{MnO}_{2}$ in 10 min. Chen [17] discussed the reduction of $\mathrm{KMnO}_{4}$ in $\mathrm{H}_{2} \mathrm{SO}_{4}$ solution at temperature of $70-95{ }^{\circ} \mathrm{C}$ for $30 \mathrm{~min}$, the chemical reaction between potassium permanganate and sulfuric acid can be formulated as:

$$
\begin{gathered}
\mathrm{MnO}_{4}-+8 \mathrm{H}^{+}+5 \mathrm{e}^{-}==\mathrm{Mn}^{2+}+4 \mathrm{H}_{2} \mathrm{O} \\
2 \mathrm{MnO}_{4}-+3 \mathrm{Mn}^{2+}+2 \mathrm{H}_{2} \mathrm{O}==5 \mathrm{MnO}_{2}+4 \mathrm{H}^{+}
\end{gathered}
$$

It showed low $\mathrm{pH}$ of the reaction system would prohibit the formation of $\mathrm{MnO}_{2}$. Therefore, a neutral or weak acid system medium is preferable for such reaction. 


\subsection{The Possible Mechanism of $\mathrm{KMnO}_{4}$ Immobilization on BT-3}

The probable reaction of $\mathrm{KMnO}_{4}$ reduction in weak acidic condition could be written as follows:

$$
\mathrm{MnO}_{4}-+4 \mathrm{H}^{+}+3 \mathrm{e}^{-}==\mathrm{MnO}_{2}+2 \mathrm{H}_{2} \mathrm{O}
$$

The $\mathrm{MnO}_{2}$ formed from the reduction of $\mathrm{KMnO}_{4}$ could be adsorbed on the BT-3. However, contrary to the reduction of $\mathrm{KMnO}_{4}$ with homogeneous catalytic oxidation, as shown in Equation (3), this study aimed to investigate the reduction of $\mathrm{KMnO}_{4}$ with heterogeneous catalysis by iron oxide, which is seldom discussed in the literature.

According to $\mathrm{Ma}$ and $\mathrm{Lin}[18,19]$, the reduction of $\mathrm{KMnO}_{4}$ could proceed in two possible stages. In the first stage, the BT-3 surface was positively charged via hydrolysis in acidic condition. $\mathrm{MnO}_{4}{ }^{-}$ions were absorbed, thereby producing a heterogeneous $\mathrm{MnO}_{4}{ }^{-}$film on the BT-3.

$$
\begin{gathered}
\equiv \mathrm{FeOOH}+\mathrm{H}^{+} \rightarrow \equiv \mathrm{FeOOH}_{2}^{+} \\
\equiv \mathrm{FeOOH}_{2}{ }^{+}+\mathrm{MnO}_{4}{ }^{-} \rightarrow \equiv \mathrm{FeOOH}_{2}-\mathrm{MnO}_{4}
\end{gathered}
$$

Moreover, Chou et al. [20], proposed that iron is generated as $\mathrm{Fe}^{2+}$ by reductive dissolution of $\mathrm{FeOOH}$. Therefore another possible mechanism is proposed for the acid condition.

$$
\begin{gathered}
\mathrm{FeOOH}(\mathrm{s})+3 \mathrm{H}^{+}+\mathrm{e}^{-} \rightarrow \mathrm{Fe}^{2+}+2 \mathrm{H}_{2} \mathrm{O} \\
3 \mathrm{Fe}^{2+}+\mathrm{MnO}^{4-}+4 \mathrm{OH}^{-}+3 \mathrm{H}_{2} \mathrm{O} \rightarrow 3 \mathrm{Fe}(\mathrm{OH})_{3}(\mathrm{~s})+\mathrm{MnO}_{2}(\mathrm{~s})+\mathrm{H}^{+}
\end{gathered}
$$

\subsection{Kinetics of $\mathrm{KMnO}_{4}$ Decomposition}

The results concerning the immobilization of $\mathrm{KMnO}_{4}$ at $\mathrm{pH}_{\mathrm{i}}=2.5$ in the presence of $100 \mathrm{~g}$ BT-3 particles are presented in Figure 7.

Figure 7. First-order fit of $\mathrm{KMnO}_{4}$ decomposition for different concentrations of $\mathrm{KMnO}_{4}$.

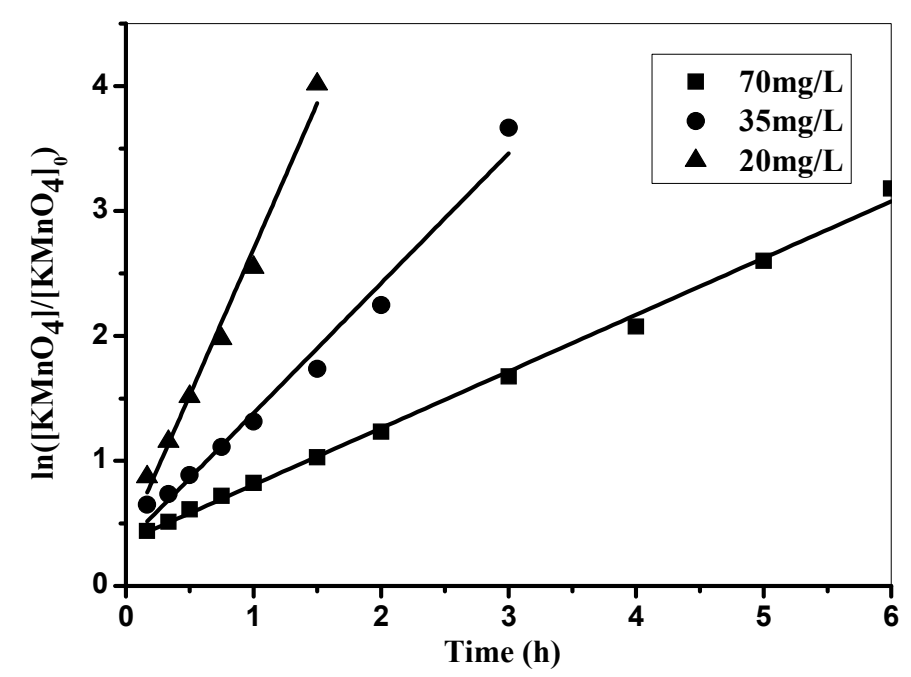

The logarithmic $\mathrm{KMnO}_{4}$ concentration is plotted as a function of the reaction time for different initial concentrations of $\mathrm{KMnO}_{4}$, ranging from 20 to $70 \mathrm{mg} / \mathrm{L}$. The well fitted data to a straight line indicates that the decomposition of $\mathrm{KMnO}_{4}$ in the presence of BT-3 follows a first-order kinetic rate law: 


$$
-\mathrm{d}\left[\mathrm{KMnO}_{4}\right] / \mathrm{dt}=\mathrm{k}\left[\mathrm{KMnO}_{4}\right]
$$

thus $\ln \left[\mathrm{KMnO}_{4}\right] /\left[\mathrm{KMnO}_{4}\right]_{0}=-\mathrm{kt}$

where $\mathrm{k}$ is the observed first-order rate constant and $\left[\mathrm{KMnO}_{4}\right]$ and $\left[\mathrm{KMnO}_{4}\right]_{0}$ are the concentrations of $\mathrm{KMnO}_{4}$ in the solution at any time $\mathrm{t}$ and time zero, respectively. The lines were treated by linear regression, which produced correlation coefficients $>0.982$. Furthermore, the $\mathrm{k}$ is $2.34,1.04$ and 0.45 when the concentration of $\mathrm{KMnO}_{4}$ is 20,35 and $70 \mathrm{mg} / \mathrm{L}$, respectively.

Obviously, initially the first-order date did not intersect with the origin; this is probably due to the trace amounts of $\mathrm{Fe}^{2+}$ on the surface of BT-3 which could accelerate the reduction in the short term. To prove this, $\mathrm{Fe}^{2+}$ with a molar ratio $\mathrm{Fe}: \mathrm{Mn}=2: 1$, was added in the same experiment but without $\mathrm{BT}-3$ (date not shown), the $\mathrm{KMnO}_{4}$ was reduced in $10 \mathrm{~min}$, then almost maintained at the same level.

\section{Conclusion}

A new and novel Mn-Fe binary oxide was synthesized using a fluidized bed reactor. In the binary system, through in situ monitoring of the $\mathrm{KMnO}_{4}$ concentration, the decomposition of $\mathrm{KMnO}_{4}$ in the presence of BT-3 follows a first-order kinetic rate law. Low $\mathrm{KMnO}_{4}$ concentration is advantageous in increasing the reduction rate, which decreased from 2.34 to 0.45 when the $\mathrm{KMnO}_{4}$ concentration was 20 and $70 \mathrm{mg} / \mathrm{L}$, respectively. High BT-3 dosage could also be favorable to the reduction rate. Furthermore, the optimum pHi condition for the immobilization of $\mathrm{KMnO}_{4}$ is 6 , and $\mathrm{KMnO}_{4}$ could be virtually reduced in $10 \mathrm{~min}$. Finally, a possible mechanism of $\mathrm{KMnO}_{4}$ immobilization, where the BT-3 was found to act as the substrate and reduction agent, was proposed.

\section{References}

1. Banerjee, K.; Amy, G.L.; Prevost, M.; Nour, S.; Jekel, M.; Gallagher, P.M.; Blumenschein, C.D. Kinetic and thermodynamic aspects of adsorption of arsenic onto granular ferric hydroxide (GFH). Water Res. 2008, 42, 3371-3378.

2. Chen, R.; Zhi, C.; Yang, H.; Bando, Y.; Zhang, Z.; Sugiur, N.; Golberg, D. Arsenic (V) adsorption on $\mathrm{Fe}_{3} \mathrm{O}_{4}$ nanoparticle-coated boron nitride nanotubes. J. Colloid Interface Sci. 2011, 359, 261-268.

3. Simeonidis, K.; Gkinis, T.; Tresintsi, S.; Martinez-Boubeta, C.; Vourlias, G.; Tsiaoussis, I.; Stavropoulos, G.; Mitrakas, M.; Angelakeris, M. Magnetic separation of hematite-coated $\mathrm{Fe}_{3} \mathrm{O}_{4}$ particles used as arsenic adsorbents. Chem. Eng. J. 2011, 168, 1008-1015.

4. Tang, Y.; Wang, J.; Gao, N. Characteristics and model studies for fluoride and arsenic adsorption on goethite. J. Environ. Sci. 2010, 22, 1689-1694.

5. Yang, W.; Kan, A.T.; Chen, W.; Tomson, M.B. pH-dependent effect of zinc on arsenic adsorption to magnetite nanoparticles. Water Res. 2010, 44, 5693-5701.

6. Youngran, J.; Fan, M.; van Leeuwen, J.; Belczyk, J.F. Effect of competing solutes on arsenic(V) adsorption using iron and aluminum oxides. J. Environ. Sci. 2007, 19, 910-919.

7. Zhang, J.S.; Stanforth, R.S.; Pehkonen, S.O. Effect of replacing a hydroxyl group with a methyl group on arsenic (V) species adsorption on goethite ([alpha]-FeOOH). J. Colloid Interface Sci. 2007, 306, 16-21. 
8. Manning, B.A.; Fendorf, S.E.; Bostick, B.; Suarez, D.L. Arsenic(III) oxidation and Arsenic(V) adsorption reactions on synthetic birnessite. Environ. Sci. Technol. 2002, 36, 976-981.

9. Nesbitt, H.W.; Canning, G.W.; Bancroft, G.M. XPS study of reductive dissolution of $7 \AA$-birnessite by $\mathrm{H}_{3} \mathrm{AsO}_{3}$, with constraints on reaction mechanism. Geochim. Gosmochim. Acta 1998, 62, 2097-2110.

10. Scott, M.J.; Morgan, J.J. Reactions at oxide surfaces. 1. Oxidation of As(III) by synthetic birnessite. Environ. Sci. Technol. 1995, 29, 1898-1905.

11. Zhang, G.S.; Qu, J.H.; Liu, H.J.; Liu, R.P.; Li, G.T. Removal mechanism of As(III) by a novel Fe-Mn binary oxide adsorbent: Oxidation and sorption. Environ. Sci. Technol. 2007, 41, 4613-4619.

12. Zhang, G.; Qu, J.; Liu, H.; Liu, R.;Wu, R. Preparation and evaluation of a novel Fe-Mn binary oxide adsorbent for effective arsenite removal. Water Res. 2007, 41, 1921-1928.

13. Wu, K.; Wang, H.; Liu, R.; Zhao, X.; Liu, H.; Qu, J. Arsenic removal from a high-arsenic wastewater using in situ formed Fe-Mn binary oxide combined with coagulation by poly-aluminum chloride. J. Hazard. Mater. 2011, 185, 990-995.

14. Huang, Y.H.; Shih, Y.J.; Chang, C.C. Adsorption of fluoride by waste iron oxide: The effects of solution $\mathrm{pH}$, major coexisting anions, and adsorbent calcination temperature. J. Hazard. Mater. 2011, 186, 1355-1359.

15. Huang, Y.H.; Hsueh, C.L.; Cheng, H.P.; Su, L.C.; Chen, C.Y. Thermodynamics and kinetics of adsorption of $\mathrm{Cu}$ (II) onto waste iron oxide. J. Hazard. Mater. 2007, 144, 406-411.

16. Huang, Y.H.; Hsueh, C.L.; Huang, C.P.; Su, L.C.; Chen, C.Y. Adsorption thermodynamic and kinetic studies of $\mathrm{Pb}$ (II) removal from water onto a versatile $\mathrm{Al}_{2} \mathrm{O}_{3}$-supported iron oxide. Sep. Purif. Technol. 2007, 55, 23-29.

17. Chen, Y.; Liu, C.; Li, F.; Cheng, H.M. Preparation of single-crystal [alpha]- $\mathrm{MnO}_{2}$ nanorods and nanoneedles from aqueous solution. J. Alloy. Compd. 2005, 397, 282-285.

18. Ma, S.B.; Ahn, K.Y.; Lee, E.S.; Oh, K.H.; Kim, K.B. Synthesis and characterization of manganese dioxide spontaneously coated on carbon nanotubes. Carbon 2007, 45, 375-382.

19. Lin, S.S.; Gurol, M.D. Catalytic decomposition of hydrogen peroxide on iron oxide: Kinetics, mechanism, and implications. Environ. Sci. Technol. 1998, 32, 1417-1423.

20. Chou, S.; Huang, C.; Huang, Y.H. Heterogeneous and homogeneous catalytic oxidation by supported $\gamma$-feooh in a fluidized-bed reactor: Kinetic approach. Environ. Sci. Technol. 2001, 35, 1247-1251.

(C) 2012 by the authors; licensee MDPI, Basel, Switzerland. This article is an open access article distributed under the terms and conditions of the Creative Commons Attribution license (http://creativecommons.org/licenses/by/3.0/). 